\title{
Imaging of Arthritis and Metabolic Bone Disease
}

Barbara N. Weissman, MD, Editor. Philadelphia: Saunders (Elsevier), 2009, 749 pages, $\$ 179.00$ US

This well illustrated text is authored by 58 musculoskeletal radiologists. The emphasis is on medical disease rather than orthopedics. Sections are devoted to General Imaging Principles, Degenerative and Traumatic Conditions (inflammatory and metabolic conditions are covered under this section), Metabolic Conditions (i.e., issues of abnormal bone metabolism), and Interventions. The organization is not oriented to rheumatology, but the information and particularly the illustrations are helpful. I found that my understanding of radiological principles was upgraded by reviewing the work. Although some of the physiology requires better foundation knowledge to comprehend fully, the text was easily digestible. The book and illustrations can be accessed online by the purchaser so that the material can be used in many ways.

The rheumatology perspective for a text such as this might have included validated measures for disease progression (Sharp score, etc.), utility of radiological techniques for early diagnosis, and therapeutic intervention or differential diagnosis of radiological findings. Most of this is missing.

Overall, I would highly recommend the book. I continue to read it to upgrade my observations. I think that the descriptions provide more insight than many similar efforts put out by rheumatologists. In effect the book allows the medical specialist to access some of the perspectives and expertise of the MSK radiologist.

ARTHUR BOOKMAN, MD, Toronto Western Hospital, University Health Network, Toronto, Ontario, Canada. E-mail: arthur.bookman@uhn.on.ca

J Rheumatol 2011;38:5; doi:10.3899/jrheum.110001 